\title{
ONLINE RECOMMENDATION SYSTEMS' USAGE BY COMPANIES IN BALTIC COUNTRIES
}

\author{
Elina Gaitniece ${ }^{1}$
}

\begin{abstract}
Global retailers are using sophisticated online recommendation systems (ORS) which enhance customers' loyalty towards the specific site. Online markets in Baltic countries are growing fast, but Baltic e-commerce sites are not using a wide enough range of eWOM tools. The aim of this paper is - to evaluate how eWOM through ORS is perceived and used by digital marketing specialists and e-commerce players in the Baltics. Research methods used were: literature analysis on ORS's influence on consumer purchase decisions, and an expert survey and monitoring study. The research results revealed major barriers for advanced ORS usage in the Baltics, as they discovered a gap between experts' opinion and the current reality in the Baltics. The article provides recommendations to online retailers in the Baltics on improvements that are needed.
\end{abstract}

JEL Classification Numbers: M31, M39; DOI: http://dx.doi.org/10.12955/cbup.v5.913

UDC Classification: 658.8

Keywords: recommendation system, eWOM, Baltic countries

\section{Introduction}

The fast development of digital media during the last decades provides consumers a wide choice of opinions originating from many diverse sources. Today consumers are not only consumers, they are also producers of new information online (Flanagin \& Metzger, 2013). Word of mouth communication, in general, has been recognized as an important influencer for consumers' purchasing decisions, and is thought to influence 20-50\% of all purchasing decisions (Berger, 2013) (Strauss \& Frost, 2014). Recent research shows that the influence of eWOM is growing hand in hand with the growth of a range of different communication channels and tools (Oestreicher-Singer \& Sundararajan, 2012). From the range of eWOM tools, one type are online recommendation systems (ORS), whose systems can be very basic or highly advanced. Pine (1995) states that ORS are a critical factor increasing consumer's loyalty towards the specific e-retail site. And it is also known that one of the main sources of eWOM communication is online reviews which have become an important tool of marketing communication due to the fact that many consumers search online reviews before making their purchase (Park \& Lee, 2009) (Chatterjee, 2001). But online retailers in the Baltics are only utilising the potential of ORS in very small extent. This is because of the prevailing opinion that consumers in the Baltics only tend to leave negative reviews.

But, the specifics of the online market is that borders are open, global players are stepping in and competing along with local retailers. All while, effectively working ORS systems which help a consumer to make the right decision, might become a competitive disadvantage for online shops which are not yet using them.

Due to this, the aim of this paper was - to evaluate how eWOM through ORS is perceived and used by digital marketing specialists and e-commerce players in the Baltics. To reach the aim, some tasks were defined: 1) to check previous studies on ORS influence to purchase journey; 2) to interview digital marketing experts and e-commerce players; 3) to prepare recommendations for ORS usage in the Baltics.

\section{Literature review}

As defined by Burrow (2012) WOM is sharing of information between consumers through different communication tools, frequently also called "storytelling". In the past, oral communication was almost the only way how to transfer information, but after the invention of writing and other communication tools, WOM processes have become more advanced, and hence it is not anymore linked so much with the "mouth" part of equitation (Burrow \& Fowler, 2012).

The power of WOM has already been recognized long ago in the marketing world. As Berger stated WOM is the primary factor in 20-50\% of all purchase decisions (Berger, 2013) and is already a multibillion dollar industry by itself. But today's consumers are sharing their opinions with more than just

\footnotetext{
${ }^{1}$ Faculty of Business, University of Latvia, elina.gaitniece@ gmail.com
} 
their friends and family; consumers can learn from complete strangers who shared their opinion in the digital environment. This is frequently referred as eWOM.

When a consumer wants to get an info about some product - he can "Google it", post a question on a social network site, read online customer reviews or do other online activities which will provide a wide range of "consumer experiences" in the form of eWOM (Kaufman \& Horton, 2015). eWOM encompasses a wide range of different forms and technologies (e.g., blogs, tweets, and shopping bots) of which online reviews are the most accessible and most frequently used (Thurau et al., 2004).

Online customer reviews are an important source of product information, and consumers rely on these reviews to infer product quality and to make purchase decisions. The influence of online customer reviews compels online retailers to use review systems that allow purchasers of the product to share their experiences with others by posting product reviews on the website (Pang \& Qiu, 2016). Online ratings are a quantitative summary of experiences, attitudes, and opinions usually expressed as stars or points whereas, reviews are open-ended, user-generated text messages about a product or service. The two forms can occur separately or in combination. The most prominent example of online ratings and online reviews is that by online retailer Amazon.com. (Floh et al., 2013). Gathering knowledge about online consumers is becoming a critical success factor for businesses and online recommendation systems are one of a large range of tools to do so (Liao \& Chang, 2016).

An experiment done by Senecal and Nantel showed that ORS have a strong influence not only on loyalty but also on consumers' purchasing decisions. Results showed that subjects who viewed product recommendations selected recommended products twice as often as subjects who did not consult recommendations. The experiment also showed that an online recommendation source in the form of a "recommender system" was more influential than traditional recommendation sources even when perceived as possessing less expertise than human experts and as being less trustworthy than other consumers (Senecal \& Nantel, 2004).

Schafer et al. (1999) worked out a classification system for ORS, which divided ORS into four major groups - non-personalized; attribute based; item-to-item correlation based, and people-to-people correlation based. Systems are measured and compared by two dimensions level of automation and the level of persistence in the recommendations as visible in Figure 1.

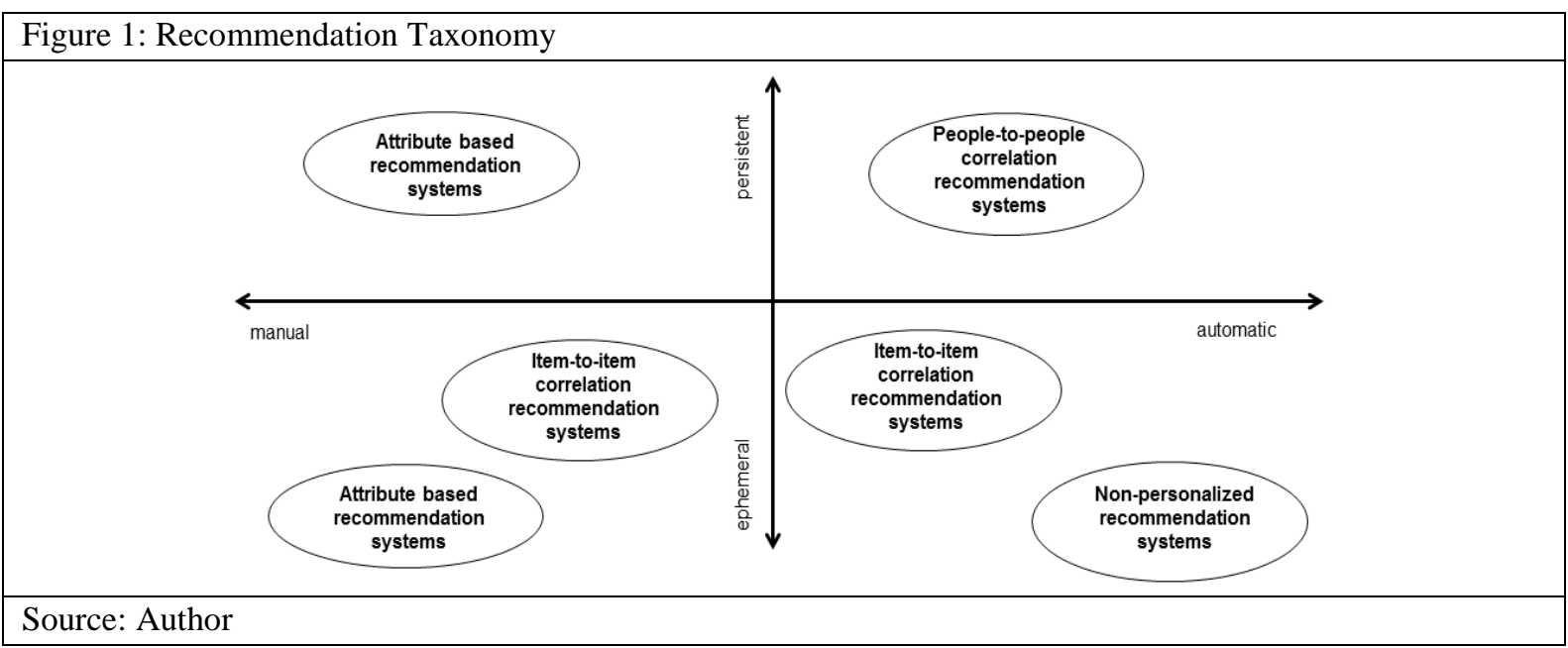

The most simple form is non-personalized ORS - this just takes into account feedback received from other customers, and where everybody gets the same offer. The next level, - attribute based ORS makes choices based on attributes searched by a particular customer and analyses syntactic properties of products to offer. The next level of ORS (item-to-item correlation ORS) takes into account customer's behavior during his previous visits. And the most sophisticated level is people-to people correlation ORS which seeks correlation between habits of different customers (Schafer, Konstan, \& Riedl, 1999). According to Oestreicher et al., (2012) people-to people correlation ORS is very effective and triples purchases of complimentary products. Also, Senecal and Nantel (2004) proved with an experiment that ORS influences a lot of consumers purchasing intentions - consumers who 
were reading recommendations purchased recommended products twice as often as those who did not read recommendations. It also showed that ORS systems were more influential than human advisors.

\section{Data and methodology}

A survey of 53 digital marketing specialists in the Baltics was carried out during February and May 2016, and further on followed up by a monitoring study. The author used a purposive nonprobability sampling method and selected digital marketing specialists by using a range of professional contacts. The group included e-commerce owners and digital marketing specialists. Twenty-seven e-commerce owners representing all three Baltic countries got an invite to participate in the survey, sixteen of them provided answers. The group of digital marketing specialists was smaller, twenty-six specialists from the Baltics were invited to participate and thirteen provided their opinion. Latvia was represented by fifteen responses, Lithuania - by ten and Estonia - by only four. Due to the small number of responses gathered on country by country level - all conclusions were done only on a Baltic level and hence there was no possibility to compare responses between countries. Further on, 15 e-commerce retailers in the Baltics were monitored and their usage of ORS was evaluated using Schafer's classification.

\section{Results and Discussion}

Survey results revealed that specialists in the Baltics recognize the impact of ORS - highest scores were given to the basic level of ORS "consumer reviews and ratings" - sixty-six percent of specialists rated them as "high" or "very high" influencers of consumers' decision making about the purchase.

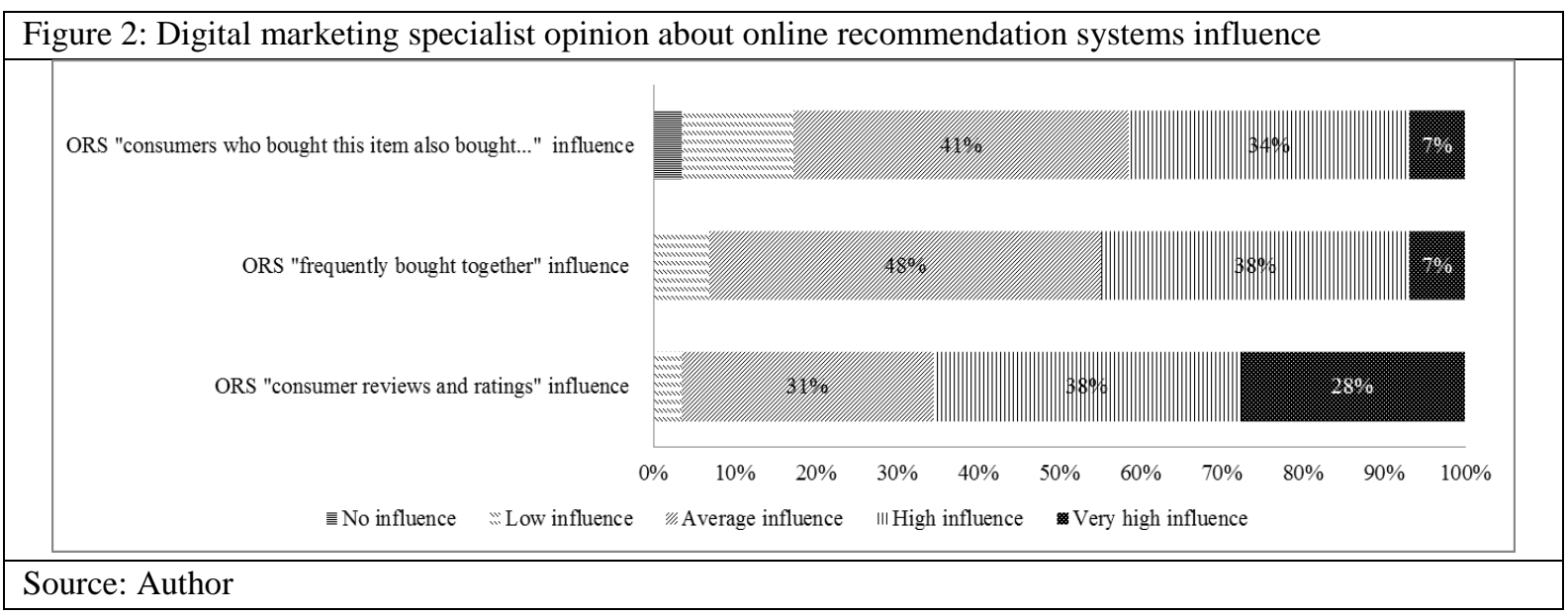

As Figure 2 shows ORS "frequently bought together" was evaluated as high or very high influencer by $45 \%$ of surveyed specialists. The most sophisticated ORS has the highest influence on consumer decision if compared with another advanced ORS "consumers who bought this item also bought..." was recognized as important influencer only by forty-one percent of specialists.

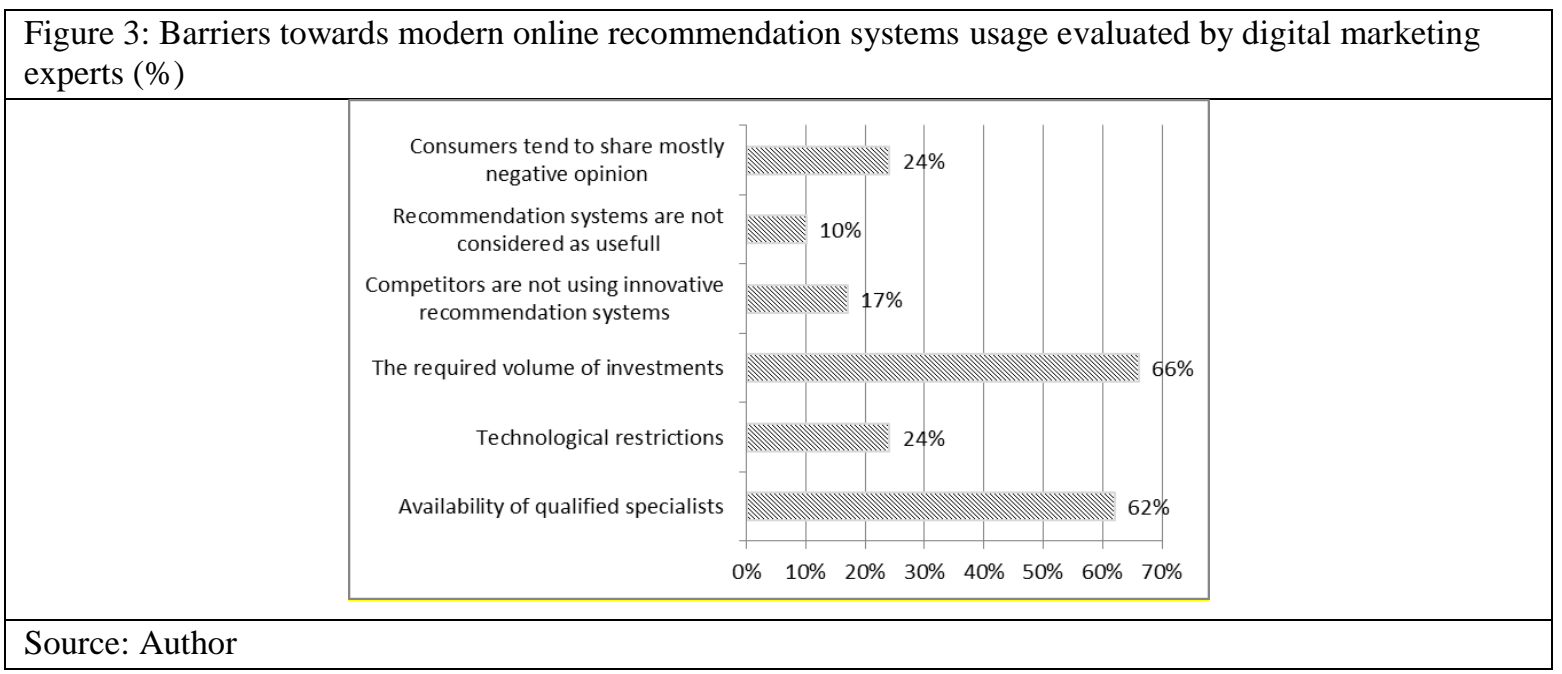

An important barrier to starting using sophisticated ORS was the recognized value of needed investments and also the availability of good and qualified specialists. As Figure 3 shows other 
obstacles got much lower scores. Additionally, it was mentioned by respondents that management attitude plays an important role in decision to go for advanced ORS in an e-shop. The previous assumption of the restrictive factor that the perception about consumers leaving mostly negative reviews was not proven, as only twenty-four percent of specialists mentioned this as an obstacle. It is also worth it to mention that the majority of specialists recognize that competitors - mostly global online players are already using quite sophisticated ORS. Additionally, monitoring studies covering both pure player and "brick\&click" channel e-commerce players revealed that there exist even retailers who do not use any ORS, whereas the majority uses only one type of ORS (usually the basic one) and there is no online retailer who would use more than 2 types of online recommendation systems. The most popular system was the attribute based online recommendations system as it was used by $47 \%$ of online shops monitored. The author also recognized that this study might produce different results if some specific product group would be selected and that the results might also change over the time. Still, it was recognized that online recommendation system usage level in the Baltics seriously lacks behind from the level reached by global e-commerce players.

\section{Conclusion}

The study revealed that previous research in the field confirms that eWOM through different online recommendation systems is an important influencer to the consumer during his decision journey particularly on the alternative evaluation phase - which brand and product to choose from several options, and also on the purchase phase - widening range of considered alternatives and possibly enlarging purchase basket. The survey results also confirm that online marketing specialists in the Baltics recognize the importance of ORS, it did not confirmed the previous assumption that ORS in the Baltics are not used due to expected negative reviews from consumers. Instead there were several other factors mentioned as barriers to using advanced ORS in e-commerce sites in the Baltics. Most relevant barriers- value of needed investment and availability of qualified specialists. Because of this, the usage of ORS in local online shops is very limited. Therefore, the author suggests to online retailers who are competing in the Baltic market, side by side with global players, to start using the most advanced ORS to keep their customer loyalty and not to lose momentum when first time users make their first purchases and get used to certain helping tools which guide them through their purchase decision journey. This study will be continued by a wide consumer survey which will identify factors which consumers find relevant in influencing them in online recommendation systems.

\section{References}

Berger, J. (2013). Contagious: Why Things Catch On. New York: Simon \& Schuster.

Berger, J., Sorensen, A. T., \& Rasmussen, S. J. (2010). Positive Effects of Negative Publicity: When Negative Reviews Increase Sales. Marketing Science, 29(5), 815-827.

Burrow, J. L., \& Fowler, A. R. (2012). Marketing. Boston: Cengage Learning.

Chatterjee, P. (2001). Online reviews: do consumers use them? Advances in Consumer Research Volume, 28, 129-133.

Flanagin, A. J., \& Metzger, M. J. (2013). Trusting expert- versus user-generated ratings online: The role of information volume, valence, and consumer characteristics. Com puters in Human Behavior, 29, 1626-1634.

Floh, A., Koller, M., \& Zauner, A. (2013). Taking a deeper look at online reviews: The asymmetric effect of valence intensity on shopping behaviour. Journal of Marketing Management, 29, 646-670.

Kaufman, I., \& Horton, C. (2015). Digital Marketing: Integrating Strategy and Tactics with Values. New York: Routledge. Liao, S.-h., \& Chang, H.-k. (2016). A rough set-based association rule approach for a recommendation system for online consumers. Information Processing and Management(52), 1142-1160.

Oestreicher-Singer, G., \& Sundararajan, A. (2012). The Visible Hand? Demand Effects of Recommendation Networks in Electronic Markets. Management Science, 58(11), 1963 - 1981.

Pang, J., \& Qiu, L. (2016). Effect of Online Review Chunking on Product. International Journal of Electronic Commerce, 20(3), 355-383.

Park, C., \& Lee, T. (2009). Information direction, website reputation and eWOM effect: A moderating role of product type. Journal of Business Research, 62(1), 61-67.

Pine, B. J., Peppers, D., \& Rogers, M. (1995). Do You Want to Keep Your Customers Forever? Boston: Harvard Business Review Press.

Schafer, J. B., Konstan, J., \& Riedl, J. (1999). Recommender Systems in E-Commerce. New York: Proceedings of the 1st ACM conference on Electronic commerce.

Senecal, S., \& Nantel, J. (2004). The influence of online product recommendations on consumers online choices. Journal of Retailing, 80(2), 159-169.

Strauss, J., \& Frost, R. (2014). E-Marketing. Harlow: Pearson Education Limited.

Thurau, T. H., Gwiner, K., Walsh, G., \& Gremler, D. (2004). Electronic word-of-mouth via Consumer-opinion Platforms: What Motivates Consumers To Articulate Themselves on the Internet? Journal of Interactive Marketing, 38-53. 